EXTENDED REPORT

\title{
Macular microholes: pathogenesis and natural history
}

\author{
H J Zambarakji, P Schlottmann, V Tanner, A Assi, Z J Gregor
}

Br J Ophthalmol 2005;89:189-193. doi: 10.1136/bjo.2004.052084

See end of article for authors' affiliations

.....................

Correspondence to: Dr H J Zambarakii, Massachusetts Eye and Ear Infirmary, Angiogenesis Laboratory, 325

Cambridge Street, Boston, MA 02114, USA; HZ@meei_harvard.edu

Accepted for publication 28 July 2004

\begin{abstract}
Aims: To study the natural history and evaluate optical coherence tomography (OCT) and the retinal thickness analyser (RTA) in patients with macular microholes.

Methods: The medical records of 22 patients with a well demarcated red intraretinal foveal or juxtafoveal defect were reviewed. Fluorescein angiography (FA), RTA, and OCT were performed. The main outcome measures were visual acuity (VA), and OCT and RTA characteristics of microholes. Long term follow up was available in 13 eyes of 12 patients.

Results: The patients had a mean age of 50 years and a mean refractive error of -0.93 dioptres. The presenting symptom was a central scotoma in 14 eyes and metamorphopsia in eight eyes. All patients had a corrected VA ranging from $20 / 16$ to $20 / 125$, with 20 out of 24 eyes (83\%) having a VA $\geqslant 20 / 40$. Symptoms remained stable or improved in 16 out of 22 patients (72\%). OCT 2 findings were normal but an abnormality of the outer retina and/or a defect of the retinal pigment epithelium (RPE) were demonstrated on OCT 3 in 15 of 18 eyes (83\%). The RTA topographic map demonstrated a defect at the site of the microhole in two out of 12 eyes.

Conclusion: Although biomicroscopic examination suggested an inner foveal defect, the OCT 3 scans demonstrated a localised abnormality of the outer retina and/or RPE which could not be resolved using OCT 2. Macular microholes have a favourable long term prognosis with stable VA. Bilateral involvement is uncommon.
\end{abstract}

M acular microholes have been described in patients presenting with mildly reduced visual acuity, a central scotoma, and metamorphopsia. The term "microhole" was coined by Cairnes and McCombe $^{1}$ who described a series of patients with an apparent foveal defect in the internal limiting membrane and neuroepithelium located near the centre of the capillary free zone of the fovea centralis. These lesions had a red appearance and well defined margins, but depth was difficult to determine. Reddy et al later described a series of 14 patients with small reddish 50-133 $\mu \mathrm{m}$ full thickness macular holes which they also termed microholes, and attributed these to acute anteroposterior vitreous traction with resulting avulsion of the central fovea, based on the presence of vitreofoveal separation (VFS) and a corresponding operculum. ${ }^{2}$ More recently, normal OCT findings were reported by Douglas et al in four patients who presented with a foveal or juxtafoveal red single irregular lesion with sharply defined borders, these lesions were termed a "foveal spot". ${ }^{3}$ The lesion size was approximately $100 \mu \mathrm{m}$ and appeared to be intraretinal. ${ }^{3}$ More importantly, the lesions described by Douglas et al differed from other foveal lesions such as macular holes or solar retinopathy. ${ }^{3}$ However, it is difficult to reconcile the sharply defined negative scotoma with a defect of the inner neuroretina.

We now describe the clinical findings of macular microholes in 22 patients with long term follow up in 12 patients. A focal defect of the outer band of high OCT signal indicating an abnormality of the outer retina and/or RPE are shown in the majority of patients using OCT 3 .

\section{PATIENTS AND METHODS}

The medical records of a consecutive series of 22 patients who were diagnosed with a small, well demarcated intraretinal foveal or juxtafoveal red lesion were reviewed. Patients were invited to re-attend for further follow up examination; a detailed assessment of presenting symptoms including a description of the size and features of their scotoma, age, previous ocular history, and past medical history was reviewed. Long term follow up was available in 12 out of 22 patients. The study was approved by the Moorfields Eye Hospital Research Ethics Committee and informed consent was obtained from each participating patient.

All patients received a complete ocular examination by two of the authors (HJZ and ZJG), including best corrected visual acuity using the Early Treatment Diabetic Retinopathy Study (ETDRS) chart, slit lamp biomicroscopy, intraocular pressure measurement, and dilated fundus examination using a 78D Volk lens or a super 66 Volk lens. The recorded visual acuity was the Snellen equivalent of the smallest line read with one or no error, using chart 1 for the right eye and chart 2 for the left eye. All patients were tested using an Amsler chart to assess the location and size of the scotoma. The presence of a complete posterior vitreous detachment (PVD) was diagnosed if a Weiss ring was present on indirect binocular microscopy. The Watzke-Allen test was performed in all patients.

OCT (Carl Zeiss Ophthalmic Systems, Dublin, CA, USA) assessment was performed in 21 out of 24 eyes using OCT 2 and the Stratus OCT 3. The OCT scan is a two dimensional, cross sectional, high resolution retinal image, obtained by assembling multiple z-axis scans to generate each image. OCT 3 scans are obtained by assembling $512 \mathrm{z}$-axis scans, with an $\mathrm{X}-\mathrm{y}$ plane resolution of $20 \mu \mathrm{m}$. Composite OCT images using OCT 2 consist of a linear array of $100 \mathrm{z}$-axis scans and have an $\mathrm{x}-\mathrm{y}$ plane resolution of $50 \mu \mathrm{m}$ (Schuman JS, American Academy of Ophthalmology, Subspecialty Day, 2002). OCT was also used to evaluate the vitreoretinal interface to detect VFS. Six radial OCT scans measuring $6 \mathrm{~mm}$ in length each were performed by one of the authors (PS). If no abnormality was found, a repeat examination using multiple horizontal scans was performed.

Abbreviations: $F A$, fluorescein angiography; $O C T$, optical coherence tomography; PVA, posterior vitreous detachment; RTA, retinal thickness analyser; VA, visual acuity; VFS, vitreofoveal separation. 
RTA assessment using model $4.10 \mathrm{sp} 2$ (Talia Technology Ltd, Neve-llan, Israel) was performed in 12 out of 24 eyes. RTA scans were centred on the fovea; the three dimensional topographic maps were examined specifically for a localised defect that would correspond to the observed macular microhole. FA was performed in four eyes of four patients.

\section{RESULTS}

The clinical characteristics of patients are summarised in table 1. Twenty four eyes of 22 patients of equal sex distribution were included in this series; two patients had bilateral involvement. The mean age of the patients was 50 years (range 28-77 years). The mean refractive error was -0.93 dioptres (range -5.25 to +1.75 dioptres). Corrected visual acuity ranged from $20 / 16$ to $20 / 125$ with a mean of $20 / 31$ and 20 of the 24 eyes (83\%) had a visual acuity $\geqslant 20 / 40$. Long term follow up was available in 12 patients and varied from 2 months to 8 years (mean 4 years).

A central scotoma was the presenting symptom in 14 eyes, and metamorphopsia in eight eyes. Upon further questioning, a total of 15 patients admitted having metamorphopsia, which was confirmed on Amsler chart testing. Micropsia and macropsia were present in two patients. Eleven patients had difficulty reading and two patients were asymptomatic (table 1). The duration of symptoms for all 22 patients varied from 2 months to 10 years, with a mean of 3 years.

Of 22 patients $(72 \%), 16$ became less symptomatic or remained unchanged. Three patients had worsening symptoms which were unexplained in patients 9 and 15 (patient 15 was diabetic with no visible retinopathy), and were associated with bilateral concentric visual field loss in patient 20 , who is currently undergoing neuro-ophthalmic investigation. Three patients were subjectively worse as a result of mild cataract (patient 11), macular pucker (patient 12), and idiopathic intracranial hypertension (patient 21). In 12 patients with long term follow up, the scotoma was small and typically remained stable or became smaller over time.

We routinely enquired about sun gazing and direct trauma to the head or the eye. One patient gave a vague history of sun gazing as a child (patient 3 ). Two patients briefly glanced at a solar eclipse in the UK using protective eyewear (patients 6 and 10). The history and findings on examination were not consistent with a diagnosis of solar retinopathy in any of the above three patients. Patient 10 had a past medical history of meningioma excision with optic nerve compression 15 years prior to her current presentation. The patient made a full recovery following the neurosurgical intervention. Patients 15 and 18 suffered from non-insulin dependent diabetes without any retinopathy.

In 13 eyes of 12 patients with long term follow up, corrected VA at the first visit ranged from 20/16 to 20/80 with a mean of 20/34. Corrected VA at last follow up ranged from $20 / 16$ to $20 / 125$, with a mean of $20 / 33$ in the affected eye (fig 1), and from 20/16 to 20/32 in the fellow (non-affected) eye with a mean of $20 / 19$.

On examination, biomicroscopy suggested the presence of a red, well demarcated intraretinal foveal or juxtafoveal defect, measuring 50-100 $\mu \mathrm{m}$ (fig 2). None of the patients had a complete PVD. VFS was present in seven of the 21 eyes examined by OCT (fig 3). All patients were phakic. None of the patients demonstrated any retinal haemorrhage, lipid or exudate, full thickness macular hole, or operculum. The lesions did not change in appearance with long term follow up.

Fluorescein angiography (table 2) was performed in four eyes. Patient 19 had early hyperfluorescence superior to the anatomic centre of the macula, consistent with a small RPE window defect but not localised to the macular microhole. Three patients had normal FA. There was no evidence of vascular disease, no late leakage, and the RPE was healthy in all four eyes examined.

Table 1 Patient characteristics and clinical information

\begin{tabular}{|c|c|c|c|c|c|c|c|c|c|c|c|}
\hline Patient & Age & Sex & Eye & Refraction & $\begin{array}{l}\text { Initial } \\
\text { VA }\end{array}$ & $\begin{array}{l}\text { VA at follow } \\
\text { up }\end{array}$ & $\begin{array}{l}\text { Fellow } \\
\text { eye }\end{array}$ & $\begin{array}{l}\text { Duration follow } \\
\text { up (months) }\end{array}$ & $\begin{array}{l}\text { Presenting } \\
\text { symptoms }\end{array}$ & $\begin{array}{l}\text { Duration of } \\
\text { symptoms }\end{array}$ & Other \\
\hline 1 & 53 & $\mathrm{~F}$ & $\mathrm{R}$ & -5.25 & $20 / 20$ & $20 / 20$ & & 0 & Metamorphopsia & 12 months & \\
\hline 1 & 53 & $\mathrm{~F}$ & $\mathrm{~L}$ & -5.25 & $20 / 20$ & $20 / 20$ & & 0 & Scotoma & 5 years & \\
\hline 2 & 55 & $\mathrm{~F}$ & $\mathrm{~L}$ & -1.0 & $20 / 30$ & $20 / 30$ & $20 / 20$ & 0 & Metamorphopsia & Asymptomatic & Idiopathic finding \\
\hline 3 & 31 & $M$ & $\mathrm{R}$ & 0.0 & $20 / 16$ & $20 / 16$ & $20 / 16$ & 36 & Scotoma & 10 years & $\begin{array}{l}\text { Vague history of sun } \\
\text { gazing during childhood }\end{array}$ \\
\hline 4 & 57 & $\mathrm{~F}$ & $\mathrm{R}$ & -1.25 & $20 / 30$ & $20 / 25$ & $20 / 16$ & 96 & Scotoma & 7 years & \\
\hline 5 & 29 & $\mathrm{~F}$ & $\mathrm{~L}$ & -0.5 & $20 / 30$ & $20 / 16$ & $20 / 16$ & 27 & None & Asymptomatic & Idiopathic finding \\
\hline 6 & 36 & $\mathrm{~F}$ & $\mathrm{R}$ & -0.5 & $20 / 40$ & $20 / 32$ & $20 / 20$ & 42 & Scotoma & 4 years & $\begin{array}{l}\text { Glanced at eclipse } \\
\text { protected }\end{array}$ \\
\hline 7 & 28 & $M$ & $\mathrm{~L}$ & 0.0 & $20 / 30$ & $20 / 30$ & $20 / 16$ & 0 & scotoma & 7 months & \\
\hline 8 & 51 & $M$ & $\mathrm{R}$ & 0.0 & $20 / 40$ & $20 / 25$ & $20 / 20$ & 34 & Metamorphopsia & 4 years & \\
\hline 9 & 57 & $\mathrm{~F}$ & $\mathrm{~L}$ & 0.75 & $20 / 40$ & $20 / 63$ & $20 / 25$ & 7 & Scotoma & 3 years & \\
\hline 10 & 53 & $\mathrm{~F}$ & $\mathrm{R}$ & -0.5 & $20 / 60$ & $20 / 50$ & $20 / 16$ & 3 & Scotoma & 12 months & $\begin{array}{l}\text { Meningioma, glanced } \\
\text { at eclipse protected }\end{array}$ \\
\hline 11 & 61 & $M$ & $L$ & 1.0 & $20 / 40$ & $20 / 40$ & $20 / 16$ & 0 & Scotoma & 18 months & Cortical lens opacity \\
\hline 12 & 68 & $\mathrm{~F}$ & $\mathrm{R}$ & 0.75 & $20 / 60$ & $20 / 40$ & $20 / 32$ & 80 & Metamorphopsia & 8 years & $\begin{array}{l}\text { Cortical lens opacity, } \\
\text { macular pucker }\end{array}$ \\
\hline 13 & 30 & $\mathrm{~F}$ & $\mathrm{~L}$ & -1.25 & $20 / 30$ & $20 / 30$ & $20 / 20$ & 0 & Metamorphopsia & 36 months & \\
\hline 14 & 77 & $M$ & $\mathrm{R}$ & 1.75 & $20 / 40$ & $20 / 40$ & $20 / 25$ & 0 & Scotoma & 6 months & \\
\hline 15 & 49 & $M$ & $\mathrm{~L}$ & 0.0 & $20 / 30$ & $20 / 40$ & $20 / 16$ & 80 & Scotoma & 10 years & NIDDM 2 years \\
\hline 16 & 53 & $M$ & $\mathrm{R}$ & -3.0 & $20 / 32$ & $20 / 32$ & $20 / 20$ & 0 & Scotoma & 12 months & \\
\hline 17 & 50 & $\mathrm{~F}$ & $\mathrm{R}$ & 1.25 & $20 / 80$ & $20 / 40$ & $20 / 20$ & 2 & $\begin{array}{l}\text { Metamorphopsia, } \\
\text { scotoma, and } \\
\text { difficulty reading }\end{array}$ & 5 months & \\
\hline 18 & 69 & $M$ & $\mathrm{R}$ & 0.5 & $20 / 60$ & $20 / 40$ & $20 / 25$ & 84 & Metamorphopsia & 4 years & NIDDM 4 years \\
\hline 19 & 48 & $M$ & $\mathrm{R}$ & -3.5 & $20 / 40$ & $20 / 40$ & $20 / 16$ & 0 & Metamorphopsia & 11 months & \\
\hline 20 & 50 & $M$ & $\mathrm{R}$ & 0.25 & $20 / 20$ & $20 / 80$ & & 74 & None & 6 months & $\begin{array}{l}\text { Unexplained bilateral } \\
\text { visual field loss }\end{array}$ \\
\hline 20 & 50 & $M$ & $\mathrm{~L}$ & 0.75 & $20 / 30$ & $20 / 125$ & & 74 & Difficulty reading & 7 years & \\
\hline 21 & 35 & $\mathrm{~F}$ & $\mathrm{R}$ & -1.5 & $20 / 30$ & $20 / 30$ & $20 / 16$ & 0 & Scotoma & 12 months & $\| \mathrm{H}$ \\
\hline 22 & 69 & $M$ & $\mathrm{R}$ & -4.0 & $20 / 25$ & $20 / 25$ & $20 / 20$ & 0 & Scotoma & 2 months & \\
\hline
\end{tabular}

$\mathrm{F}$, female; $M$, male; L, left; $\mathrm{R}$, right; NIDDM, non insulin dependent diabetes; $I \mathrm{H}$, idiopathic intracranial hypertension. 


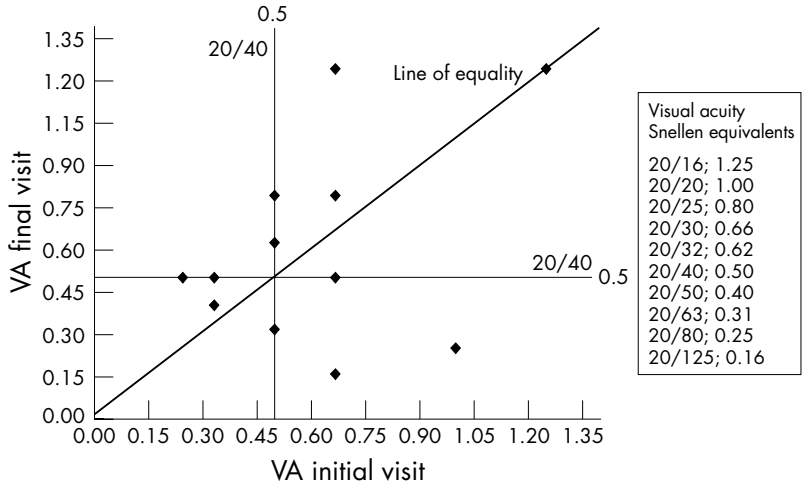

Figure 1 Scatter plot graph for 13 eyes of 12 patients with long term follow up. Visual acuity at last follow up versus VA at the initial presentation is shown. Nine out of 13 eyes $(69 \%)$ achieved a VA of $20 / 40$ or better at last follow up. Four eyes deteriorated (patients 9, 10, and 20 (both eyes)).

OCT (table 2) was performed in 21 eyes. Seven patients were examined using OCT 2. No abnormality was detected using OCT 2 in any of them (fig 3A). Five patients had a repeat examination using OCT 3 , four of whom showed a defect of the outer band of high reflectivity suggestive of a defect of the outer retina and/or RPE (patients 3,4,8, and 10, fig 3). ${ }^{4}$ A total of 18 eyes of 17 patients were assessed with OCT 3. Fifteen of the 18 eyes examined by OCT $3(83 \%)$ showed a similar abnormality with a defect of the outer retina and/or the RPE (figs 2 and 3). ${ }^{4}$ One patient was found to have a lamellar defect of the inner retina (patient 14).

RTA assessment (table 2) was performed in 12 eyes. The three dimensional topographic maps of the RTA scans were normal in nine eyes and abnormal in three eyes (fig 4). Two patients (patients 10 and 19) had a local depression adjacent to the anatomic fovea that corresponded to the location of the foveal microhole identified on clinical examination (fig 4). Patient 14 had a lamellar hole with an incompletely operculated flap on OCT and a corresponding abnormal RTA scan.
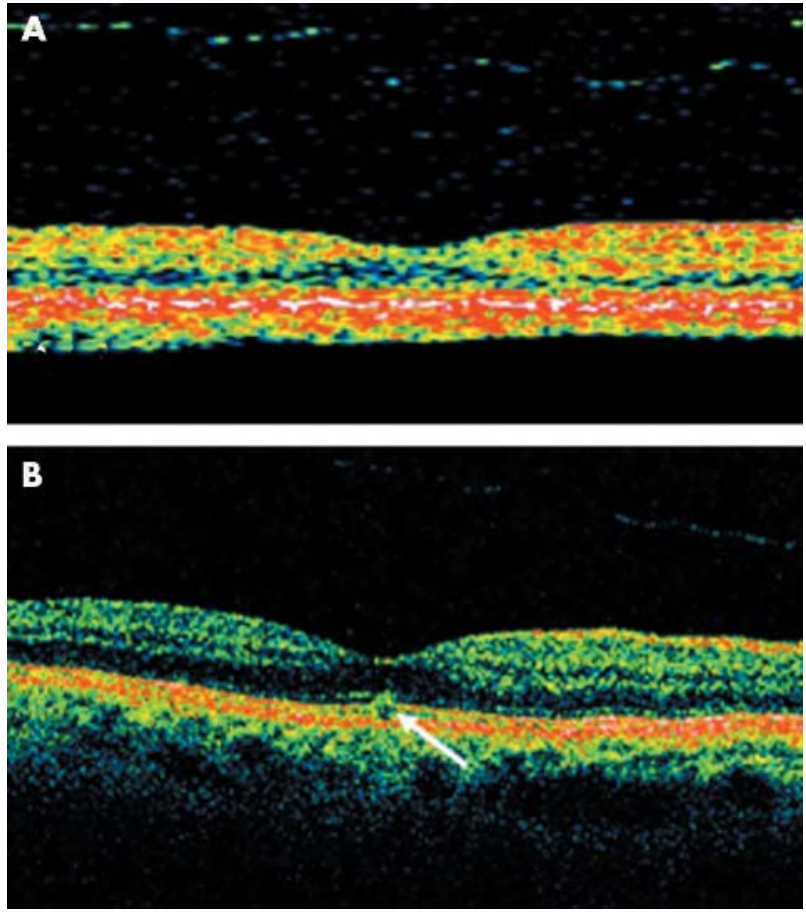

Figure 3 OCT scans of the right eye of patient 4. (A) OCT 2 shows the presence of vitreofoveal separation (VFS) but no outer retinal or RPE abnormality. (B) OCT 3 demonstrates VFS as well as a defect of the outer retina and/or RPE (arrow).

\section{DISCUSSION}

The diagnosis of a microhole can easily be overlooked without a careful history and examination. The majority of our patients presented with minimal symptoms, usually a central scotoma but occasionally metamorphopsia or reduced reading vision. Unless bilaterally affected, most patients were not significantly inconvenienced. Visual acuity was stable in the subgroup of patients with long term follow up. Clinical examination revealed a well defined red spot at the fovea or just off the anatomic centre of the macula; this clinical entity
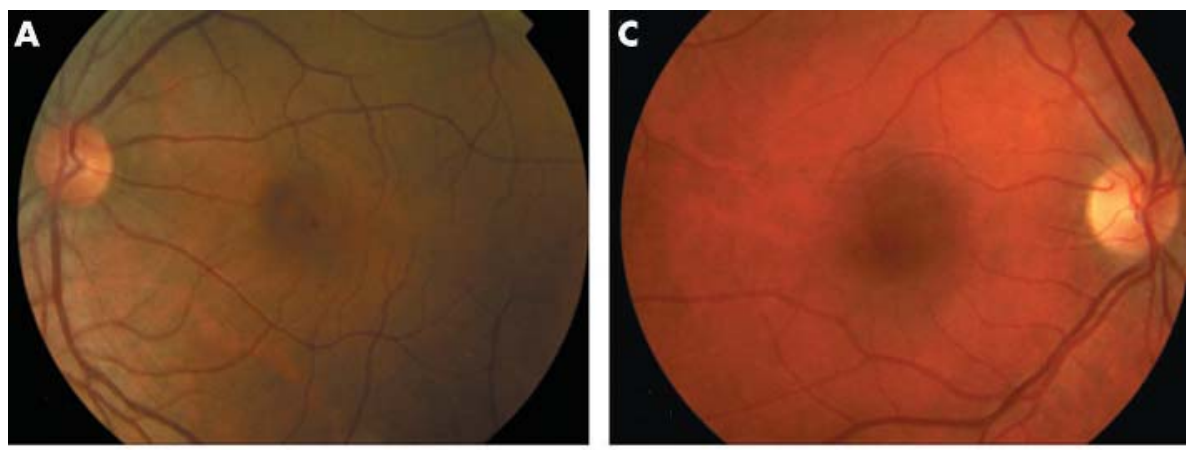

Figure 2 Fundus photograph of the left (A) and right (C) eyes demonstrate a well localised, irregular, small red lesion at the centre of the fovea; the respective OCT scans ( $B$ and $D$ ) demonstrate a well demarcated defect (arrow) at the outer retina and/or RPE level (patients 11 and 3).
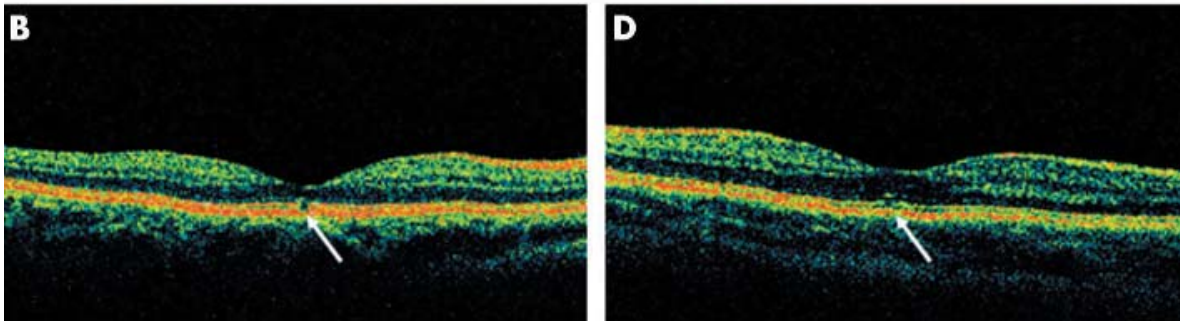
Table 2 Fluorescein angiography, optical coherence tomography, and retinal thickness analysis findings

\begin{tabular}{|c|c|c|c|c|}
\hline Patient & FFA & ОСт Model 2 & OCT Model 3 & RTA \\
\hline 1 (RE) & & NAD* & & \\
\hline 1 (LE) & & NAD* & & \\
\hline 2 & NAD & & & \\
\hline 3 & NAD & NAD $\dagger$ & Outer retina and/or RPE defect† & \\
\hline 4 & & NAD $\dagger$ & Outer retina and/or RPE defect & \\
\hline 5 & & NAD* & & \\
\hline 6 & & NAD $\dagger$ & NAD + & NAD \\
\hline 7 & & & & \\
\hline 8 & & NAD + & Outer retina and/or RPE defect† & NAD \\
\hline 9 & & & Outer retina and/or RPE defect & \\
\hline 10 & & NAD + & Outer retina and/or RPE defect† & Depression adjacent to fovea \\
\hline 11 & & & Outer retina and/or RPE defect & NAD \\
\hline 12 & & & Outer retina and/or RPE defect & NAD \\
\hline 13 & & & NAD & NAD \\
\hline 14 & & & $\begin{array}{l}\text { Lamellar hole, outer retina } \\
\text { and/or RPE defect }\end{array}$ & Abnormal \\
\hline 15 & & & Outer retina and/or RPE defect & NAD \\
\hline 16 & & & Outer retina and/or RPE defect & NAD \\
\hline 17 & NAD & & NAD & \\
\hline 18 & & & Outer retina and/or RPE defect & NAD \\
\hline 19 & $\begin{array}{l}\text { RPE window } \\
\text { defect }\end{array}$ & & Outer retina and/or RPE defect & Depression adjacent to fovea \\
\hline 20 (RE) & & & Outer retina and/or RPE defect & \\
\hline $\begin{array}{l}20 \text { (LE) } \\
21\end{array}$ & & & Outer retina and/or RPE defect & \\
\hline 22 & & & Outer retina and/or RPE defect & NAD \\
\hline
\end{tabular}

is therefore similar to that described by other authors, without any haemorrhage, exudates, or retinal thickening. ${ }^{13}$ We did not observe any full thickness retinal defects. OCT 3 scans demonstrated a very well localised subtle defect probably indicating the presence of a gap in the photoreceptors, and/or an RPE defect consistent with the patients presenting symptoms. The three dimensional topographic map of the RTA did not contribute any useful information,
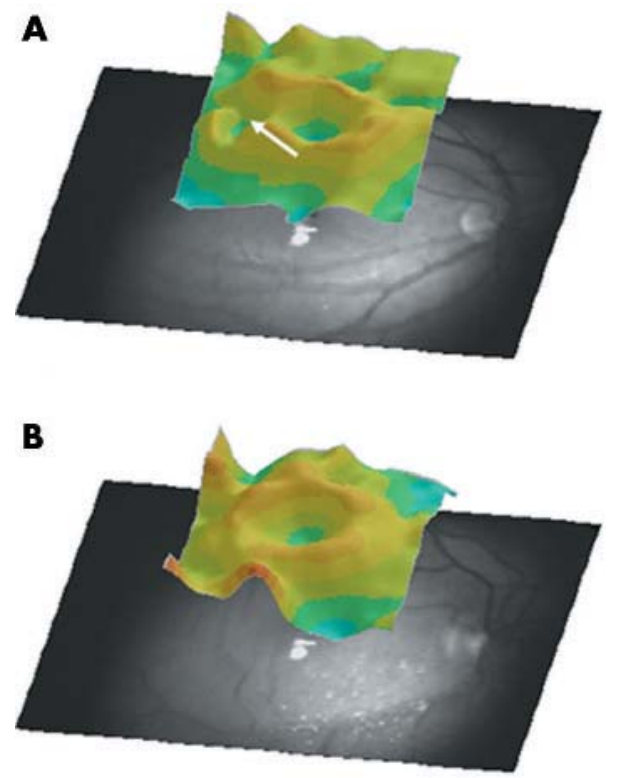

Figure 4 Three dimensional topographic map of the right eye of patient 19 using the RTA. A depression temporal to the fovea and corresponding to the microhole is shown ( $\mathrm{A}$; arrow). The three dimensional RTA map of the right eye of patient 8 is normal (B). although a localised depression at the site of the observed microhole was seen in two patients. The diagnosis of a macular microhole is a clinical diagnosis, which can be confirmed by OCT 3 in the majority of patients.

Similar clinical findings have been described in association with direct sun gazing, viewing an eclipse unprotected, and blunt trauma. ${ }^{5-8}$ Solar retinopathy however, is a well recognised clinical entity with a characteristic appearance and clinical course. RPE changes have been demonstrated on FA $^{5}$ and on histopathology. ${ }^{9}$ Using OCT, reversible hyperreflectivity of all retinal layers at the fovea after viewing an eclipse have been described ${ }^{10}{ }^{11}$ Huang et al however demonstrated chronic OCT changes following photic exposure, and showed outer retinal defects and alterations of the RPE with cystic changes very similar to those described in our patients. ${ }^{12}$ Patient 3 in our series gave a vague history of sun gazing as a child; his symptoms however, were unilateral, he gave no history of an acute onset and presented late with no evidence of parafoveal oedema. Patients 6 and 10

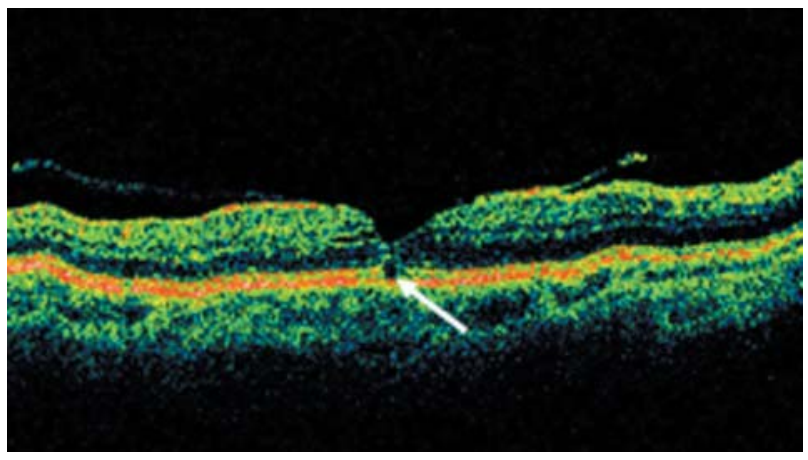

Figure 5 OCT scan of the right eye of patient 22. This demonstrates VFS but persistent attachment of the posterior vitreous face to the fovea. A localised cystic defect is present at the outer retina and/or RPE level (arrow). 
had glanced briefly at the eclipse using protective eyewear and findings were not consistent with solar retinopathy. The salient differences between a microhole and solar retinopathy have been described elsewhere. ${ }^{1}$

The patients described by Reddy et al presented with acute symptoms in $93 \%$ of cases, all lesions "appeared to be full thickness" and typically became extremely difficult to differentiate from the surrounding retina. ${ }^{2}$ However, the patients described by Cairns et al presented with vague onset of symptoms, two out of 17 were asymptomatic, the level of the retinal lesion was difficult to determine, and its morphology remained unchanged throughout follow up ${ }^{1}$. Furthermore, the presence of a PVD was only mentioned in relation to one patient with a history of trauma in the series by Cairns et al, ${ }^{1}$ but five patients had a complete PVD at the time of presentation in the series by Reddy et al, and in all patients within four weeks of follow up. ${ }^{2}$ The uncertainty about the level of the lesion within the retina, and the state of the posterior hyaloid highlight the importance of high resolution imaging using OCT. Localised VFS at the macula may be missed on cursory examination of the macula but would be identified on OCT imaging. VFS supports the view that the pathogenesis of microholes may be associated with acute posterior vitreous detachment at the macula. OCT imaging permits longitudinal imaging to assess changes in morphology over time, and can rule out retinal cysts, traction, elevation, or thinning.

Douglas et al described a series of patients with mild visual disturbances and a corresponding red foveal lesion which appeared biomicroscopically similar to those described in the original series by Cairns et al. ${ }^{13}$ In addition, no patient in either study had any evidence of a full thickness macular hole and none of the lesions changed significantly in appearance during follow up. ${ }^{13}$ Although Douglas et al identified bilateral involvement in one third of their patients, ${ }^{3}$ bilaterality was present in $<10 \%$ of other series including the present study ${ }^{2}$ A favourable final vision was shown in the present study as $77 \%$ of eyes with long term follow up achieved a VA $\geqslant 20 / 50$. Final visual acuity in other studies of microholes also showed a favourable long term prognosis as $63-100 \%$ eyes achieved a $\mathrm{VA} \geqslant 20 / 50 .{ }^{12}$

Our experience using OCT 2 showed normal cross sectional images of the central macula, as demonstrated by Douglas et al. ${ }^{3}$ The observed focal abnormalities on OCT 3 however, are likely to be the result of its improved axial $(8 \mu \mathrm{m})$ and longitudinal resolution $(20 \mu \mathrm{m})$ compared with previous versions of the same instrument (Schuman JS, American Academy of Ophthalmology, Subspecialty Day, 2002). The interpretation of the observed changes is difficult as OCT pseudocolour bands and light microscopy use different approaches to assess cellular elements. ${ }^{4}$ Furthermore, newer instruments using the same imaging principle with an axial resolution of $2-3 \mu \mathrm{m}^{13}$ represent a significant advance over commercially available OCT systems and may be more suitable to assess such defects. ${ }^{14}$

We have used the term microhole to describe these well defined foveal lesions because of the biomicroscopic appearance of an inner retinal abnormality; however the nature and the consistency of the patients' symptoms would suggest an outer retinal defect involving the photoreceptors and/or RPE. The absence of pigmentary changes on clinical examination and normal FA in the majority of patients indicates that this is not primarily a defect of the RPE. The localisation of the minute abnormality at the level of the outer retina and/or $\mathrm{RPE}$, seen on the newer OCT with its improved resolution, would be consistent with the patients' symptoms. The absence of a full thickness retinal hole on OCT is consistent with the clinical examination and absence of a positive Watzke-Allen test. The observed changes may be secondary to anteroposterior vitreofoveal traction as suggested by the presence of VFS in $33 \%$ of our patients. ${ }^{2}$ In support of this theory, patient 22 had VFS in the macular area, with a flat trampoline-like configuration and a persistent attachment at the fovea (fig 5). OCT images of perifoveal vitreous separation in eyes with stage 1 and 2 macular holes have been described..$^{15}$ The lack of progression of microholes is consistent with the lack of progression of stage 1 and 2 macular holes with vitreomacular separation. ${ }^{16}{ }^{17}$

The signs observed on OCT 3 in this series are most likely secondary to a primary event that affected the inner retina. Unlike the findings of other authors' series of microholes, ${ }^{2}$ none of our patients had a complete PVD or a full thickness macular hole and we did not observe any subretinal fluid surrounding the small foveal lesions. This OCT appearance in isolation however, is not diagnostic given that a similar appearance can be observed following successful macular hole surgery (personal communication, A Gaudric) which may support the possibility of a gap in the photoreceptors. Typically, the presenting tiny central or paracentral scotoma, relatively good VA and absence of gross macular abnormality, full thickness hole, diffuse RPE abnormalities, yellow spots or rings, microaneurysms or haemorrhage on biomicroscopy, and/or FA should indicate the possibility of a macular microhole.

In conclusion, we presented a series of patients with a well defined foveal abnormality and corresponding visual symptoms. The benign nature of a microhole is indicated by the generally well preserved and stable visual acuity over time.

\section{Authors' affiliations \\ H J Zambarakii, P Schlottmann, V Tanner, A Assi, Z J Gregor, Vitreoretinal Department, Moorfields Eye Hospital, London, UK}

The authors have no proprietary or financial interests in the work presented.

\section{REFERENCES}

1 Cairns JD, McCombe MF. Microholes of the fovea centralis. Aust N Z J Ophthalmol 1988;16:75-9.

2 Reddy CV, Folk JC, Feist RM. Microholes of the macula. Arch Ophthalmol 1996:114:413-16.

3 Douglas RS, Duncan J, Brucker A, et al. Foveal spot: a report of thirteen patients. Retina 2003;23:348-53.

4 Toth CA, Narayan DG, Boppart SA, et al. A comparison of retinal morphology viewed by optical coherence tomography and by light microscopy. Arch Ophthalmol 1997;115:1425-8.

5 Freedman J, Gombos GM. Fluorescein fundus angiography in self-induced solar retinopathy. A case report. Can J Ophthalmol 1971;6:124-7.

6 Grey RH. Foveo-macular retinitis, solar retinopathy, and trauma. Br J Ophthalmol 1978;62:543-6.

7 Wong SC, Eke T, Ziakas NG. Eclipse burns: a prospective study of solar retinopathy following the 1999 solar eclipse. Lancet 2001;357:199-200.

8 Yannuzzi LA, Fisher YL, Slakter JS, et al. Solar retinopathy. A photobiologic and geophysical analysis. Retina 1989;9:28-43.

9 Tso MO. Photic maculopathy in rhesus monkey. A light and electron microscopic study. Invest Ophthalmol 1973;12:17-34.

10 Bechmann $M$, Ehrt $O$, Thiel MJ, et al. Optical coherence tomography findings in early solar retinopathy. $\mathrm{Br} J$ Ophthalmol 2000;84:547-8.

11 Codenotti M, Patelli F, Brancato R. OCT findings in patients with retinopathy after watching a solar eclipse. Ophthalmologica 2002;216:463-6.

12 Huang SJ, Gross NE, Costa DL, et al. Optical coherence tomography findings in photic maculopathy. Retina 2003;23:863-6

13 Drexler W, Morgner U, Ghanta RK, et al. Ultrahigh-resolution ophthalmic optical coherence tomography. Nat Med 2001;7:502-7.

14 Huang D, Swanson EA, Lin CP, et al. Optical coherence tomography. Science 1991;254:1178-81.

15 Hee MR, Puliafito CA, Wong C, et al. Optical coherence tomography of macular holes. Ophthalmology 1995;102:748-56.

16 Hikichi T, Yoshida A, Akiba J, et al. Natural outcomes of stage 1, 2, 3, and 4 idiopathic macular holes. Br J Ophthalmol 1995;79:517-20.

17 Hikichi T, Yoshida A, Akiba J, et al. Prognosis of stage 2 macular holes. Am J Ophthalmol 1995;119:571-5. 